\title{
Analysis on the Architectural and Decorative Elements of Xiangxi Folk Buildings
}

\author{
Lin Liu \\ Department of Art and Design, Hunan Agricultural University, Changsha, China \\ Email address: \\ 736247673@qq.com

\section{To cite this article:} \\ Lin Liu. Analysis on the Architectural and Decorative Elements of Xiangxi Folk Buildings. History Research. \\ Vol. 6, No. 1, 2018, pp. 22-27. doi: 10.11648/j.history.20180601.13
}

Received: May 18, 2018; Accepted: July 1, 2018; Published: July 31, 2018

\begin{abstract}
This paper aimed to give an in-depth field research on the architectural and decorative elements of Xiangxi area in China. Xiangxi refers to the western region of Hunan. In Xiangxi there are unique regional culture and aesthetic features. Especially, the architectural and decorative elements are important parts of local decorative features. The components of folk buildings in Xiangxi include gable and roof ridge decoration, doors and windows, murals, roof beams and pillars are separately analyzed in detail. The decorations have the obvious geographical characteristics. It also can be found that building decorations not only have aesthetic attributes but also cultural connotations such as pursuit of happiness, disaster prevention, moral education, etiquette and other meanings. The conclusion of this research is, traditional architectural parts and decorative elements in Xiangxi have a great significance in historical and cultural levels, and owns the values of aesthetic and modern application as well.
\end{abstract}

Keywords: Xiangxi Folk Building, Building Characteristics, Building Components, Decorative Characteristics, Regional Culture

\section{Introduction}

National and regional decorative elements can provide rich themes for contemporary design. China has a long history and a large number of ethnic groups, for instance, an unique regional culture in the 'western area of Hunan' (which is also called 'Xiangxi') includes a splendid civilization that created by the nation of Tujia, Miao, Dong and other nationalities. The civilization covers the daily lives of the people of all ethnic groups, such as weaving, marriage, funeral, handicrafts and so on. And, in the perspective of material culture merely, from the village layout to the decorative patterns, many local issues can reflect the lives of the local people and their cultural speciality.

Xiangxi region includes Xiangxi Tujia \& Miao Autonomous Prefecture, Zhangjiajie, Huaihua and other places, of which the "folk building" refers to the residence of ordinary people other than the imperial residence, temples and academies. With different cultural backgrounds, buildings are constructed in different ways. In Xiangxi, there are three forms of original settlement: ancient towns, villages and stockaded houses. In such folk houses, the decorative elements are typical, and usually settled in doors, windows, columns, ceilings, ridge ornaments and other components. They can present the local national characteristics and aesthetic preferences directly.

\section{Analysis of the Architectural Components of Xiangxi Folk Buildings}

An Architecture includes exterior walls, roofs, doors and windows, murals, beams and pillars, etc. Areas communicate with each other on building components and decorations, and also retain their unique parts which reflects the local taste. In Xiangxi area, the components and decorations Has the important historical value and the esthetic value.

\subsection{Exterior Walls}

The exterior walls are also called "fire prevention walls", which is a kind of brick wall. These walls are high out of the roof to prevent burglary and the spread of fire. There are two planes on each side of its double slope roof, and the tiles on the top of the wall are piled up like mountains. The walls in 
Xiangxi area usually expose the brick layers, and some of those would brush the lime.

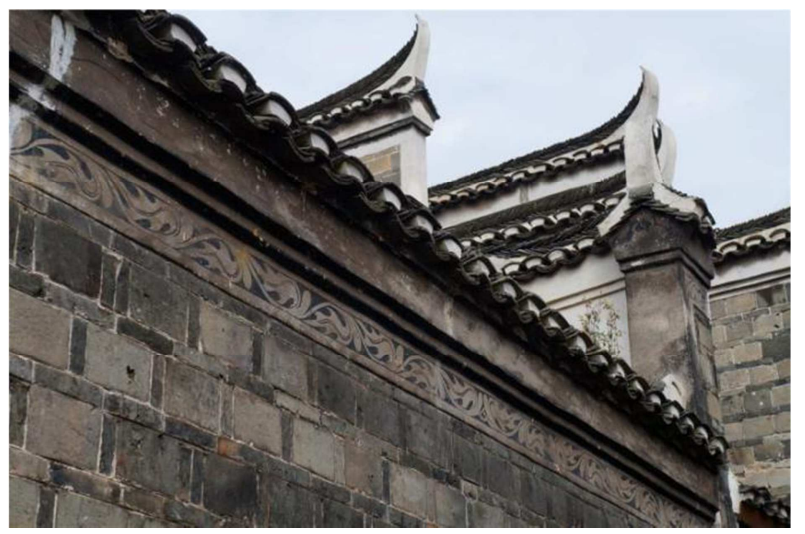

Figure 1. The exterior wall of the ancient village Gaoyi.

Horse-head wall is a kind of gable wall, which is the representative of Huizhou architecture. However, due to the influence of Huizhou Style, the ancient buildings of Xiangxi also use the horse-head wall as an external wall. The shape of the wall is similar to that of the horse head. The upper part is convex, and the lower part converges. The different height of the walls are staggered, and the vertical and horizontal side alternates each other. Under the slope roof is the main body of the wall that shaped in the form of steps. Horse-head walls can change the monotonous architectural form of the whole village. The gray wall along with the small back tiles on its top are elegant and simple. Meanwhile, on both left and right tops there is an upwarp, making the exterior wall looks lighter and active.

\subsection{Roofs and Ridges}

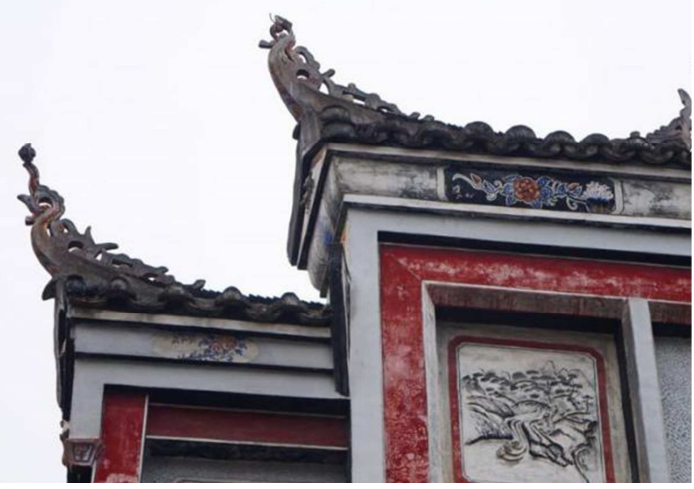

Figure 2. The ridge decoration of the ancient city Qianyang.

There are kinds of roofs in traditional buildings, such as the veranda hall roofs called Wudian is commonly used in the imperial residence, and the residence of the ordinary people is generally a slope roof, which has a simple front-and-rear structure. According to the on-the-spot investigation by the author, it can be found that one of the building forms in Xiangxi is called Yingshan, they take the horse-head wall as an external wall that lift the outer wall up above the roof for fire prevention; and the other forms of folk buildings are called Xuanshan (such as those in Furong Town and Tuojiang area), the outer wall is lower than the roof, an the eaves are stretched out, which can prevent the rain blows into the residence. [1] In addition, the arrangement of roofs in Xiangxi is various. Undulating form is commonly used in pile dwellings. There are many layers of the residence, and for each floor there is an independent roof. Crisscrossed roofs can also be seen in pile dwellings.[2] On the top of the undulating form, the small black tiles are arranged horizontally and longitudinally according to the direction of their main ridges and vertical ridges. In addition, roofs are scattered with different directions and height, and the splicing of the roof and beam is flexible, which added the structural style of local buildings.

The residential roofs in Xiangxi are mostly stacked with small green tile, with simple color and little ornate decoration. A small number of rich families decorates their roof with the grave of flowers, curly grass and grain. The local ridge ornaments stacked the top of walls with black tiles, and make a warping form at the end of the left and right side. Some houses also use lime clay sculptures to make curly flowers and plants. [1] Lime clay sculptures are cheap, simple and durable. Xiangxi residential decorations are commonly made by such a traditional technique. At the end of the warps there are delicate sculptures that can make the roof looks lighter, and the buildings more compact, and the warping roof are also benefit for indoor lighting and draining water on the roof. [3] Mixed with the culture of Han, $\mathrm{Chu}$ and $\mathrm{Wu}$, the roof ridge in Xiangxi area owns a new characteristic, which includes the elegance of $\mathrm{Chu}$ culture, the mystery of $\mathrm{Wu}$ culture, and the auspicious meaning and social hierarchy of Han Chinese culture.

\subsection{Doors and Windows}
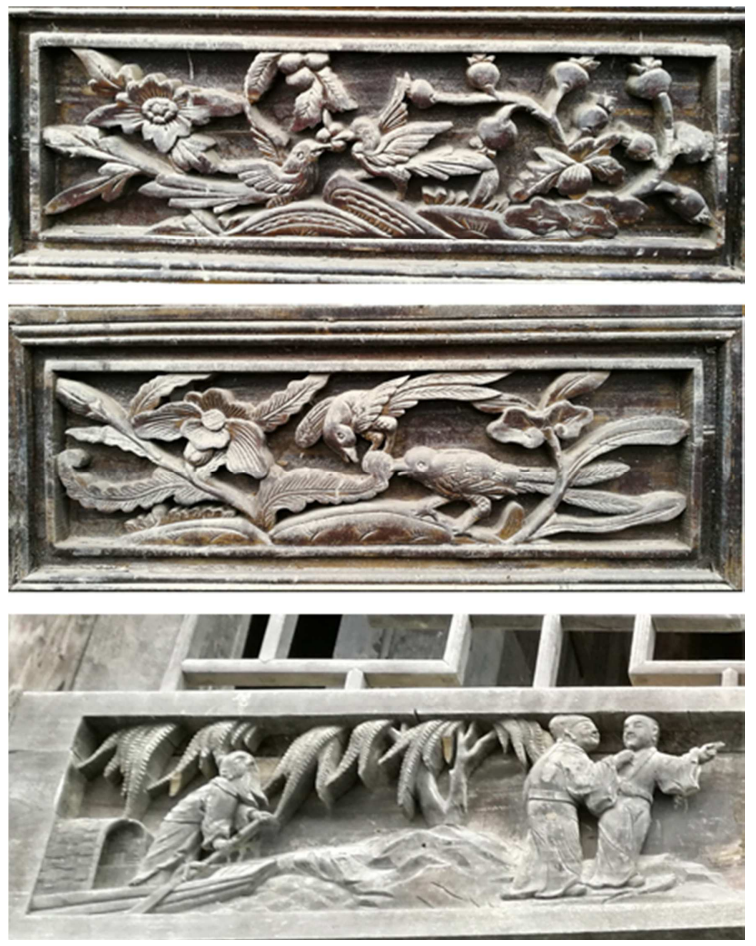

Figure 3. Doors decoration in Liye. 


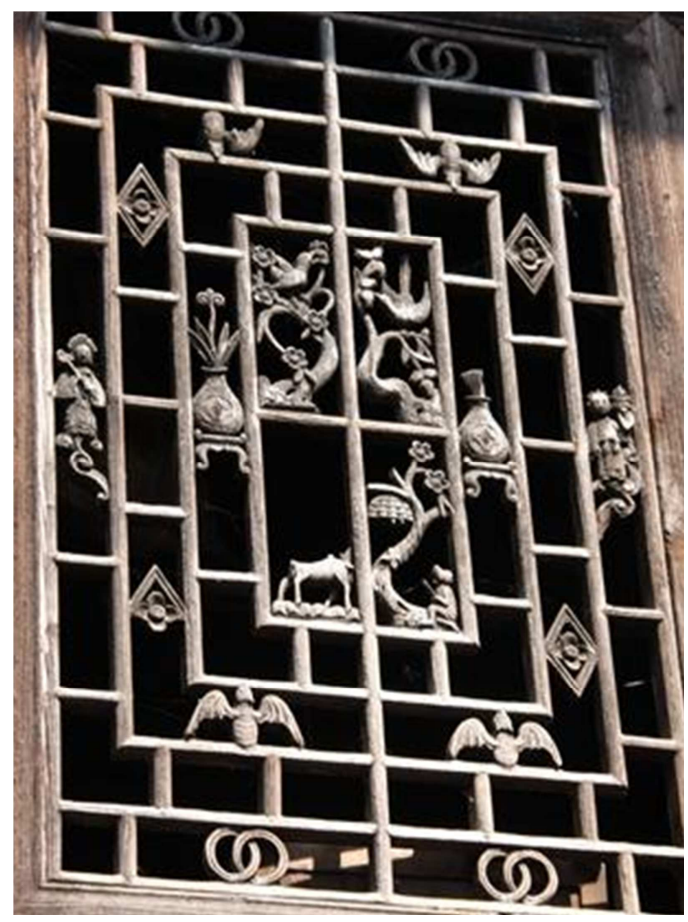

Figure 4. Window decorations in Gaoyi.

Door in the traditional Chinese society reflects the social status and wealth of the house owner, therefore the design is extremely fastidious. Folk doors in Xiangxi are constituted with the exterior gate and the internal door. The exterior gate is made of stone that has three common forms: The concave gate, which is standing under the eaves, converging in the middle and opening on both sides. The arch gate, which is standing under the archway, usually with a tall front face and decorated with steps and arches. The recessive door, which has no eaves but a few steps, is an inwardly indented entrance of the building. [4]

Ordinary residences generally do not have external doors, so the doors inside the gates are the main parts of decoration. The fan of doors in Xiangxi is usually six-bar type, and the divided two parts are different. The upper part is ventilated and the underpart is stuffy. The upper half of the door has a complex engraving of lines, flowers, birds and plants. Initially the doors were designed for ventilation and lighting, but then aesthetic features gradually increased. The lower part is a stuffy board, mostly decorated with wood relief sculpture. As for doors in Xiangxi, the tape-plate design is of the most complex. Craftsmen lay stress on the detail processing, decorating the tape-plate with complex flowers and birds, because the position of a tape-plate is the main area of sight of the pedestrian.

The window ornaments of Xiangxi also refer a regional and national character. For example, the window of the pile dwelling which is usually supported by a wooden bar can be opened from the bottom. The other kinds such as suspended windows that are towed at the bottom can be opened and closed by a rope. Such windows can prevent the water from floating into the house when it rains outside, and also ensure ventilation. There are many window decoration patterns in
Xiangxi, such as regional flowers, birds, utensils of locals, mythical stories. The advantage of them is concrete. They can be clearly and plainly described. By image analogy, homo-phonic analogy or other ways, the entity image can be given with ideological connotation. Ancient abstract characters include swastika, a square pattern called 'Hui', I-type, are commonly found in the door frame decorations and the frame structure of the window lattice. This very simple decorative patterns with a balanced composition, had used the collocation and change of points, lines, and Geometric forms. [5] These decorative elements on local doors and windows can give an aesthetic feeling of architecture, show the economic power of the house owner, and reflect the local social environment of advocating culture, education and art. The ornaments shows that Xiangxi artisans have an adeptness on carving, and presents the typical decorative themes and techniques in this area.

\subsection{Murals}

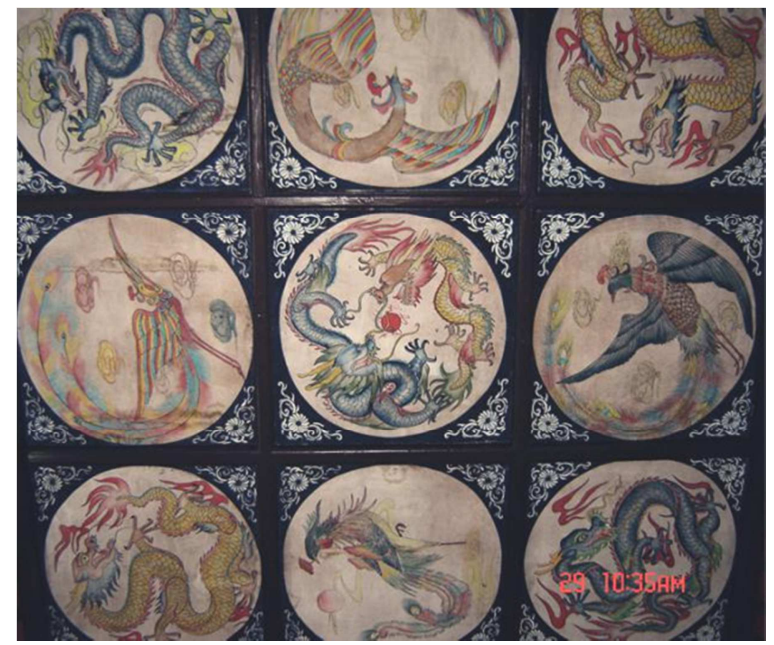

Figure 5. Ceiling painting, Yang family.

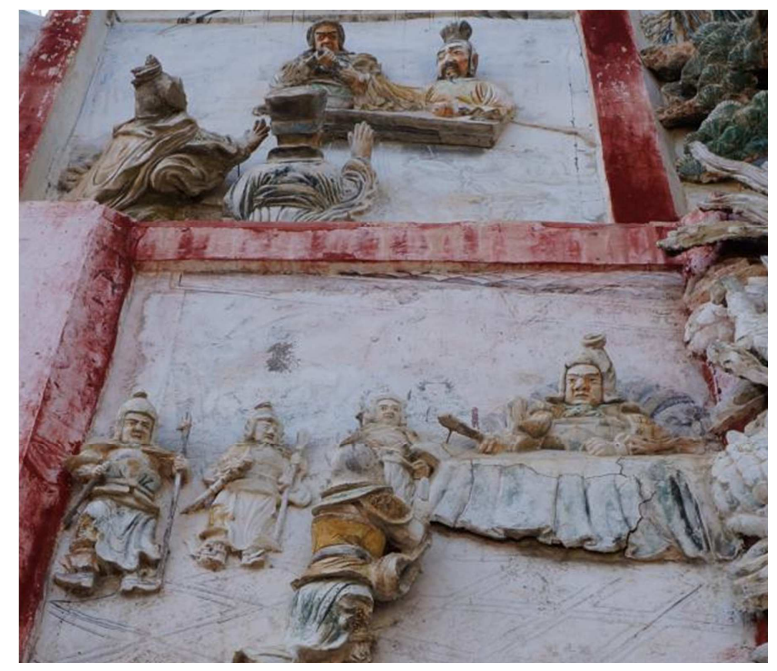

Figure 6. Clay murals, Pan family.

The ceiling painting is one of the top-surface decoration of 
traditional architecture in China. It is a major decorative form in a large building. The ceiling painting is a plane decoration. In traditional Chinese ceilings, the painting is usually divided into small units by roof beams. These painting decorations not only has the aesthetic function, but also has the role of dust-proof and heat insulation. Ceiling paintings in Xiangxi are generally painted with mythological image, and also with plain symbols as decoration. In addition, the folk ancestral hall of Xiangxi is abundant with decorative patterns which has a wide range of themes. As to the expression methods, they are not limited to color painting, and there are various forms of clay sculpture and relief sculpture. For example, in the ancient village Gaoyi, the courtyard is usually decorated with curly strips of straw by color painting. On the outer wall of the Pan family in Jingping Ancient Village, there are 3D clay statues and murals. It depicts folklore, and decorate the columns on both sides with an embossed dragon pattern. The lime clay can absorb plant pigments and mineral pigments, and the sculpture works are durable. The on-the-spot investigation shows that, murals of Xiangxi ancestral temple are usually complicated, and painted with simple and bright solid colors, makes the murals possess a high aesthetic value.

\subsection{Beams and Pillars}
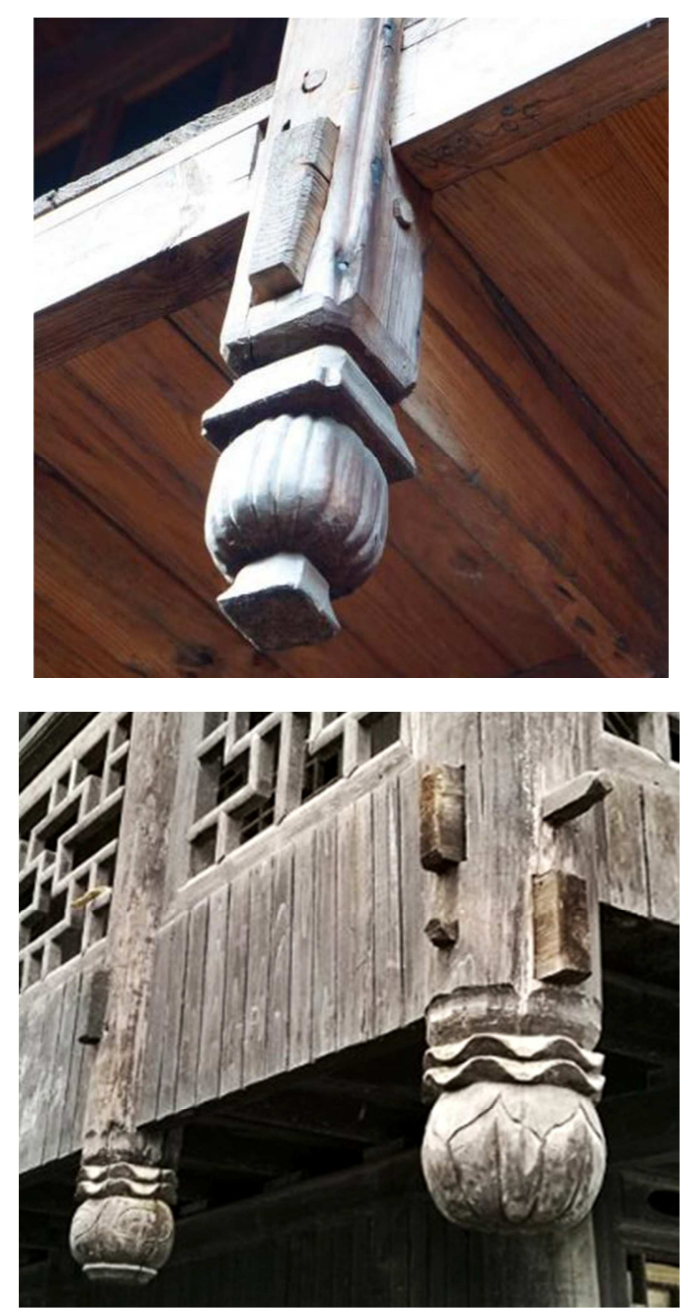

Figure 7. hanging pillar decorations.
Traditional buildings in Xiangxi area focused on the decoration of railings, beams and pillars, which are often carved with ancient $\mathrm{Z}$ patterns, 亜 patterns, 回 patterns, etc. The pillars of portico may have eight, six or four prisms. [6] the beams and pillars in ordinary families are seldom decorated, and most of them are only coated with tung oil.

Xiangxi Tujia (a minority) houses are equipped with hanging corridors, and the complete-pillar structures that sustains from the top to bottom are not common, so the pillars in Xiangxi are mostly suspended ones. The hanging pillar can transfer the load from the bottom to the top, and bear the vertical tension. The Tujia people are fond of decorating bottoms of hanging pillars. In western areas of Hunan, the bottoms of hanging pillars are usually shaped like round fruits and melons, which revealing a rustic flavor of simplicity. In addition, among the beam and the pillar, an architectural decoration called 'Queti' (sparrow brace) can not only increase the loading force of beams, prevent the beams of vertical tilting, but also enrich the form and decoration of the architecture.

\section{Analysis of the Decorative Theme and Characteristics of Xiangxi Folk Houses}

There are three decorative themes of Xiangxi folk houses: figures and stories, animals and plants, geometric patterns.

The folk decorative characters of Han nationality usually use the characters in mythical stories, which can be seen on pillars, lintels and the bottom plate of doors. They are presented in full composition, with fluent lines, and in a complete plot. The behavior of these characters reveals traditional ethics and morality, which can enlighten the young generations.

The use of animal and plant forms usually used by symbolism, homophony and other techniques can give these creatures some beautiful humanistic connotations. For example, in animal patterns, bats in Chinese cultures refer to "happiness everywhere", magpies to "happiness", fishes to "have more than needed", and deer to "affluence". [7] Among plant themes, curly-grass lines are the commonest. It strengthened the decorative features of lines by the distortion, twining, winding and extending of the grass and vines. [8] The curly-grass lines also shows the vitality of lives, which contains a beautiful association.

In addition, geometric patterns are often used to foil the figurative patterns, or structured as frames for doors and windows.

The relationship between the representation and connotation of these symbolic themes is straightforward and stable. China had kept the feudal society for a long time, so the connotation of the traditional themes usually has a strong succession, which also leads to a relatively simple and monotonous way to express the certain meaning through the certain symbols. The obvious rule is that, components with practical functions have become more and more formal and aesthetic with the development of crafting skills, and after that 
some components become purely decorations and ornaments. These components are not restricted by practical functions, and even lose their practical functions.

Architectural decoration is an important carrier of traditional and regional culture. For example, the core of the feudal etiquette culture is hierarchy. In the architecture, the hierarchy refers to the rigorous restrictions of decorative themes on architectures of different social classes. In the traditional architecture, the door and window carving are categorized as 'light' wooden works, while the shaping works of beams, pillars and roofs are classified as 'heavy' wooden works. Heavy wooden works are restricted by the concept of hierarchy, and the decorative subject matter must not exceed the authority, so the wealth and aesthetics of house owners are usually reflected only on the light wooden works, such as door and window ornaments.

\section{Discussions on the Values of Decoration Elements in Xiangxi Folk Houses}

\subsection{Historical and Cultural Values}

The folk house of Xiangxi combines the architectural and decorative features of many ethnic groups, as well as a variety of customs and cultures, and has a high degree of recognition. Traditional architectures and decorations are narrative and verifiable. They are important historical materials and the witnesses to the social and cultural development of the local society. [9] They can make the later generations be more objective on the local history and culture. Researching on the decorative elements of Xiangxi folk houses is inheriting the history and culture of Xiangxi area, which can carry forward the beauty of regional culture, and to evoke the public memory and the sense of identity of national cultures.

\subsection{Aesthetic Values}

Material selections of Xiangxi buildings are usually based on local materials, such as Chinese fir, bamboo and masonry. Local primitive construction methods retained the natural properties of the material and reflected the beauty of the material. For instance, the shapes of roofs and railings, and ceilings and beams are matched with each other, and the whole decoration is harmonious while has partial changes, showing the beauty of the architecture forms. The attics have staggered roofs, and their railings, ceilings, pillars and beams are corresponding with each other, and the whole decoration is harmonious and full of local atmosphere. Windows and doors in Xiangxi usually have wood carving decorations, with fine patterns that reflect the local crafting skills. The sparrow braces, melon-like column decorations, as well as clay sculptures and other local decorations, had reflected the beauty of the architectural details. Local carvings and paintings provide rich themes for the modern design. The aesthetic characteristics of various nationalities are well presented. It can be seen that, decorative elements of Xiangxi folk buildings have high aesthetic values in the aspects of pattern, structure, material and color. [10]

\subsection{Application Values in the Modern Society}

National and regional architectural decorations provide abundant subjects for modern design, and these decorative elements have an independent aesthetic values, so the carrier can be various and the elements can be widely used in furniture, clothing and other kinds.

In addition, human aesthetics has a certain stability. [11] It takes a long time to form an aesthetic and cultural system of a region. Some decorative elements are inherited until today, because the elements reflect the long-term aesthetic of locals, and they can give references for the further regional aesthetic research.

\section{Conclusion}

From the field research on each of the main architecture parts and the decorative elements on the architecture of Xiangxi area, it can be seen that in Xiangxi area there are unique aesthetic features that linked with rich connotations. The field research of components on Xiangxi folk buildings including gables, roof ridge decorations, doors and windows, murals, roof beams and pillars, and the special utilizing purpose and implication of the geographical characteristics are clarified in detail. The research reveals that building decorations possess aesthetic attributes, utility functions and cultural connotations. Therefore, traditional architectural and decorative parts in Xiangxi made a great contribution for the Chinese civilization historically and culturally, and have the value of modern application.

\section{References}

[1] W. Wu. An Analysis ON the Ridge Decoration Characteristics of Folk Houses in the Ancient City of Fenghuang [J]. Residence and Furniture: Vol. 2, 2005, pp. 32-35.

[2] Y. Zhang. Research on the Architectural Symbols and Modern Applications of the Traditional Residential Buildings in Western Hunan [D]. Hunan University, 2010.

[3] N. Xian, W. Ju. Analysis on the Grammatical Structure of Chinese Ancient Architectural language [J]. Furniture and Interior Decoration: Vol. 8, 2016, pp. 98-99.

[4] B. Jiang. Study on the Decoration Features of Fenghuang Traditional Architecture in Western Hunan [D]. Hunan University of Technology, 2015.

[5] N. Shi. Research on Miao decorative Art in Interior Design [D]. Nanjing University of Forestry, 2008.

[6] Y. Wei. Towns and Architectures in Western Hunan [M]. Tianjin University Press, 1995.

[7] Q. Tang. An Analysis of the Art Characteristics of Tujia Architecture in Western Hunan [J]. Vision of Fine Arts: Vol. 11, 2016, pp. 60 . 
[8] H. Xia. Study and Design Application of Window Decoration Patterns of Tujia Architectures in Western Hunan [D]. Hunan Normal University, 2015.

[9] N. Xian, D. Ni. Study on the Value of Historical Architecture [J]. Furniture and Interior Decoration: Vol. 10, 2016, pp. $112-113$.
[10] Y. Lu, L. Yu. The Application of Ancient Regional Architectural Symbols in Interior Design [J]. Furniture and Interior Decoration: Vol. 03, 2016, pp. 30-31.

[11] Q. Lou. The Ways of Decorating [M]. Beijing: Tsinghua University Press, 2011. 